\title{
ENERGY AND ENTROPY OF EXTENSION AND SPREADING OF MOBILE MONOLAYERS*
}

\author{
By Prof. William D. Harkins, Dr. T. Fraser Young, and Edward Boyd, \\ University OF Chicago
}

$\mathrm{T}$ HERMODYNAMICS reveals in two-dimensional systems a peculiar state of matter in which an extremely large amount of heat is required to increase the distance between the molecules by about thirtyfive per cent without a change of temperature or of state. In three-dimensional systems at ordinary pressures these large amounts of energy are not used unless a change of state, as from liquid to gas, occurs.

In the period of the last fifty years, much work has been done on the pressure-area relations of mobile monolayers, that is films one molecule thick, particularly those of organic substances of the general type of pentadecylic acid, or on alcohol or amine, on the surface of water. On mercury or gallium the relations are undoubtedly the same, but the experimental difficulties when a liquid metal is involved are very great. If a barrier is placed between a clean water (or mercury) surface, and the same liquid covered by a film, a force acts on the barrier from the film toward the clean surface, and this force per centimetre is considered as the surface pressure $(\pi)$. If the mean area per molecule of the monolayer is very large, as $100,000 \mathrm{~A}$. of area (sq. A.), the film is a perfect two-dimensional gas. (Ten billion A. equal one square centimetre, or sixty-five million billion, one square inch.)

On compression this two-dimensional gas begins to change to a two-dimensional liquid $\left(L_{1}\right)$ at an area of several hundred to several thousand sq. A., and is completely condensed to the liquid film at $40-50$ sq. A. and a very low film pressure. Further reduction of area results in a rapid increase of film pressure, until the liquid $\left(L_{1}\right)$ changes into a second liquid $\left(L_{2}\right)$, which has very remarkable properties, in that it is at first very highly compressible, but becomes quite incompressible if the pressure is increased sufficiently.

At a molecular area of about $20 \cdot 5 \mathrm{sq}$. A. the liquid

* Substance of a paper read at the annual meeting of the U.S. National Academy of Sciences held during April 22-23. film freezes. The remarkable fact found by the application of thermodynamics in the present work is that there is no latent heat involved in this freezing, so it differs greatly in this respect from what is found in three dimensions. Thus a kind of 'ice' is formed which requires no heat to melt it.

Thermodynamical equations have been developed, which make it possible to determine the change in either energy or entropy of these two-dimensional layers (third dimension of the order of a ten millionth of an inch) on expansion or contraction. Thus if the films are stretched (expanded) they take up heat. The work shows that when a solid film is expanded at constant temperature, and undergoes transitions from solid to liquid $\left(L_{1}\right)$, from liquid $\left(L_{1}\right)$ to liquid $\left(L_{2}\right)$, and then to gaseous film, almost all the heat is employed in two changes of area. As in three dimensions, a considerable amount of heat is utilized in the vaporization of the liquid $\left(L_{1}\right)$.

The remarkable departure from the behaviour of ordinary three-dimensional matter is that in two dimensions at constant temperature :

(1) No heat is required to melt the solid.

(2) Very little heat is required to expand the liquid $\left(L_{1}\right)$ so long as its molecules stay packed about as tightly together as in three dimensions.

(3) There then ensues an expansion of this liquid film such that the intermolecular distance may increase by so much as thirty-five per cent. This occurs without a change of state, but nevertheless the heat absorbed is very great. For example, if the film consists of pentadecylic acid this extension of the film absorbs as much heat as is used in the evaporation of the same number of molecules of water at ordinary temperatures $(11,000$ calories per mole).

(4) In the more expanded liquid state $\left(I_{2}\right)$ the heat of expansion of the film is moderately high, but only a sixth as much per unit area as in the peculiar state described in (3).

\section{BRITISH STANDARDS INSTITUTION}

$\mathrm{I}^{\mathrm{N}}$ a paper read on April 2 to the London. Branch of the Association of Mining Electrical Engineers, the significance of the work being carried on by the British Standards Institution was discussed by Mr. Percy Good, deputy director of the Institution. $\mathrm{He}$ began by paying a tribute to the foresight of British engineers who laid the foundations of a movement, which has spread to all industries and into practically every country. In Great Britain it is established on a truly democratic basis of self-government. Each industry as a whole governs for that industry; but due regard is taken as to the effect of any proposed change on other industries. Insistence on agreement between the interests concerned before a standard is promulgated has as a rule resulted in wide acceptance.

The original standardizing committee grew to be a chartered institution with more than a thousand industrial and technical committees, the pressure for more standards being continuous. The fundamental principles which govern its operation are: (1) to prepare a standard only when those concerned with the production and use of the product and material in question agree that a standard is desirable; and (2) to issue a standard only if those chiefly concerned agree that a suitable draft has been produced. 
The Council of the Institution offered the services of the Institution to the Government a few months before the outbreak of War. Considerable work, especially in connexion with war-time needs, has resulted in the issue of a special series of specifications prepared for the Ministry of Home Security (A.R.P. Department). The British Standards Institution owns certification marks as well as proprietary rights to the term 'British Standard'. Some important conclusions or principles have been reached which have been endorsed by all the constituent parts of the British Commonwealth, and have received some support in the United States, in places where a different view had previously been taken. These principles were being discussed with the European countries before the outbreak of war. It was desired to secure that certification marks of quality or performance to indicate conformity to a specification should be granted only to a recognized independent organization and not to one financially interested in the products it is desirous of marking. It was decided, also, that such marks should be used only under effective control. The B.S.I. considers it essential that any proving scheme should be on the basis of proving that the material conforms to a written specification, and should not be on the basis that the testing authority considers the material to be satisfactory.

The British Standards Institution believes that its present system has considerable possibilities and is proving a success. That system requires a maker, who is desirous of marking his goods with the B.S.I. certification mark, to maintain in operation a system of control during the process of production which will give assurance that the product always conforms to the specification. There are often safeguards and the scheme is found to add practically nothing to the cost of production.

War-time, with its restrictions, its price control, etc., provides the opportunity for eliminating those things, which accumulate and hang round an industry like a millstone. Everyone concerned with production should look into his own and his industry's ranges, and ask the B.S.I. to assist in the inquiry.

Mr. Good, in reply to Mr. W. C. Barry, said that technical proposals are referred to a committee which is expected to be rather commercially minded to ensure that the technical men's enthusiasm does not run away with them. In a number of cases, the representatives of a country have agreed to the acceptance of a proposal, but had said they could not change their national standard; and so each of these countries reserved that freedom. Mr. C. Le Maistre (director of the B.S.I.), replying to a question concerning the publication of specifications in languages other than English, said that a good deal of translation is being done by the B.S.I. into other languages.

\title{
ORIGIN OF THE SUBMARINE VALLEYS ON THE CONTINENTAL SLOPES OF THE NORTH ATLANTIC*
}

\author{
By Prof. Walter H. Bucher, \\ University of Cincinnati
}

\begin{abstract}
$\mathrm{T}$ HE essentially 'mature' topography of the continental slopes is so fresh that it is either actively forming now or has been fashioned by 'yesterday'. Being a surface pattern produced by erosion on a slope formed by deposition, it must owe its origin to a set of circumstances that either appeared for the first time or recurred after an absence sufficiently long to allow substantial progress of the sedimentation that produced the continental shelf.

Since the submarine slope topography extends to depths far greater than can be accounted for by removal of the water or vertical uplift of the shelf, the force or forces that caused the erosion must lie in the water of the ocean itself, that is, in currents. As the ocean is a standing body of water, the only currents capable of producing erosion on the continental slope are such as arise on the bottom through wave-motion of the water. Only such waves can have an effect on the sea bottom as have wave-lengths much greater than the depths at which effects are expected. Two types of such waves are known to oceanographers. Both are observed on the shore; the one as the 'tide', the other as seismic sea-waves or 'tsunami'.
\end{abstract}

Recent measurements (Stetson, Shepard and Revelle, et al.) have proved the existence of currents

* Substance of a paper read at the annual meeting of the U.S. National Academy of Sciences held during April 22-23. at great depths of an order of magnitude consistent with tidal theory. These tidal currents consist of the back-and-forth movement which results from the elongated-elliptical path that characterizes the movement of the particles in water shallow compared to the length of the waves. But, while the tidal currents are strong enough to keep the submarine valleys free from sediment, they are not strong enough to produce them. Furthermore, the tide which results from extra-telluric forces has been an essentially constant phenomenon throughout geological time. It is, therefore, not an agent that can explain the submarine slope valleys.

The tsunamic waves, on the other hand, resulting as they do from telluric forces (gravity through subaqueous landslides caused by earthquakes and submarine volcanic outbursts), are precisely of that character. They are the shoreward expression of wave-motion that originates at the bottom of the sea and therefore involves the whole column of water. Their wave-lengths, measured in hundreds of kilometres, are such that their dynamics are those of waves in shallow water. Their energy is largely dissipated when they pass from oceanic depths on to the continental shelf which, where wide enough, offers effective protection to the coastline. Even on the coast, however, the wave-motion persists for many hours and half days. 